\title{
PROFIL KONDISI FISIK ATLET PORPROV FUTSAL KABUPATEN BANGKALAN TAHUN 2019
}

\author{
Khoirul Anwar \\ Program Studi Pendidikan Olahraga, STKIP PGRI Bangkalan \\ Email: khoirul@stkippgri-bkl.ac.id \\ DOI: https://doi.org/10.36526/kejaora.v4i2.678
}

\begin{abstract}
.
Tujuan penelitian ini adalah untuk mengetahui profil kondisi fisik atlet PORPROV futsal Kabupaten Bangkalan tahun 2019. Selain untuk dasar memberikan porsi latihan, hal ini dapat digunakan juga untuk mencari solusi yang tepat untuk mengatasi permasalahan kondsi fisik yang terjadi. Penelitian ini merupakan penelitian deskriptif. Pendekatan penelitian ini menggunakan pendekatan survei. Lokasi pelaksanaan penelitian dilaksanakan di GOR SOKA Bangkalan selama proses latihan tim PORPROV futsal Kabupaten Bangkalan. Populasi dalam penelitian ini adalah seluruh atlet futsal Kabupaten Bangkalan yang mengikuti PORPROV tahun 2019 sejumlah 16 atlet. Hasil penelitian menunjukkan bahwa profil kondisi fisik atlet PORPROV futsal Kabupaten Bangkalan tahun 2019 dalam segi kelincahan termasuk dalam kategori baik sekali dengan persentase sebesar $56,25 \%$. Dalam segi kecepatan termasuk dalam kategori baik dengan persentase sebesar $75 \%$. Dalam segi kelenturan termasuk dalam kategori baik sekali dengan persentase sebesar 68,75\%. Dalam segi power termasuk dalam kategori baik dengan persentase sebesar $93,75 \%$. Sedangkan dalam segi daya tahan termasuk dalam kategori sedang dengan persentase sebesar $56,25 \%$.
\end{abstract}

Kata kunci: Kondisi Fisik, Futsal, PORPROV

\section{PENDAHULUAN}

Upaya meningkatkan prestasi olahraga semaksimal mungkin pada saat ini mendapatkan tantangan lebih banyak, baik dalam level daerah apalagi level nasional. Perkembangan futsal di Kabupaten Bangkalan saat ini mulai menggeliat kembali, terlihat dari inisiatif induk organisasi futsal Kabupaten Bangkalan yang benar-benar bekerja keras untuk mengembangkan futsal baik dari segi atlet maupun pelatih serta wasit. Salah satu bukti perkembangan tersebut adalah suksesnya gelaran Liga Futsal Kabupaten Bangkalan yang telah lama mati suri, pelatih serta wasit futsal Kabupaten Bangkalan yang mulai menatap level asia serta Iolosnya tim Futsal Kabupaten Bangkalan dalam Pekan Olahraga Provinsi (PORPROV) tahun 2019 ini.

Dalam rangka menyambut perhelatan PORPROV tahun 2019, tim futsal Kabupaten Bangkalan mempersiapkan diri dengan melatih atlet melalui latihan fisik. Salah satu faktor penting untuk meraih prestasi dalam olahraga adalah kondisi fisik, selain itu ada juga penguasaan teknik, taktik dan mental. Oleh karena itu, untuk mengetahui bentuk kondisi fisik yang dibutuhkan dan seberapa besar tingkat kondisi fisik yang diperlukan serta bagaimana meningkatkan kondisi fisik melalui latihan.

Pentingnya kondisi fisik atlet harus disadari oleh para pelatih serta atlet itu sendiri. Pelatih harus selalu menjaga kondisi fisik atlet, sehingga gangguan sekecil apapun terhadap kondisi fisik atlet sejak dini bisa terpantau. Gangguan tersebut akan mempengaruhi penampilan saat pertandingan bahkan dapat menghambat atlet dalam meraih prestasi olahraga. Perkembangan dunia futsal saat ini sangat pesat, hal tersebut dapat terlihat dari banyaknya penelenggaraan kompetisi yang diadakan baik ditinggkat daerah bahkan tingkat nasional.

Menurut Robbins dan Judge (2015) Kemampuan fisik merupakan kemampuan yang diperlukan untuk melakukan tugas-tugas yang menuntut stamina, kecekatan, kekuatan dan keterampilan serupa.

Dalam kegiatan olahraga, kondisi fisik seseorang akan sangat mempengaruhi dalam menenukan gerak penampilannya, menurut Harsono (2015) dengan kondisi fisik yang baik akan berpengaruh terhadap fungsi dan sistem 
organisasi tubuh diantaranya: 1) Akan ada peningkatan dalam kemampuan sitem sirkulasi dan kerja jantung; 2) Akan ada penigkatan kekuatan, kelentukan, stamina dan komponen fisik lainnya; 3) Akan ada ekonomi gerak yang lebih baik pada waktu lain; 4) Akan ada pemulihan yang lebih cepat dalam organisme tubuh kita apabila sewaktu-waktu respon diperlukan.

Apabila kelima keadaan di atas kurang dan tidak tercapai setelah diberi latihan kondisi fisik tertentu, maka hal itu dapat dikatakan bahwa perencanaan, sistematika, metode, serta pelaksanaannya kurang tepat.

Secara umum permainan futsal hampir sama dengan sepakbola yaitu bermain dengan kaki ke kaki, tetapi untuk penjaga gawang boleh menggunakan tangan. Yang membedakan dalam permainan ini ialah ukuran lapangan, jumlah pemain, aturan dalam permainan, dan berat bola dalam futsal.

Menurut Mulyono (2014) Secara sederhana, futsal dapat diartikan sebagai suatu permainan olahraga yang dimainkan oleh dua tim yang berbeda. Masing-masing tim beranggotakan lima orang pemain yang memainkan pertandingan dalam dua babak. Olahraga futsal ditujukan untuk membentuk perpaduan individu-individu pemain yang tergabung dalam sebuah tim demi mencapai kemenangan. Kebersamaan dan kerjasama tim sangat diperlukan dalam mencapai tujuan tersebut.

Sedankan menurut Justinus Lhaksana (2011) modern futsal adalah permainan futsal yang para pemainnya diajarkan bermain dengan sirkulasi bola yang sangat cepat, menyerang dan bertahan, dan juga sirkulasi pemain tanpa bola ataupun timing yang tepat.

Menurut John D. Tenang, (2008) teknik dasar bermain futsal meliputi; 1) Teknik Dasar Mengumpan (Passing); 2) Teknik Dasar Menahan Bola (Control); 3) Teknik Dasar Mengumpan Lambung (Chipping); Teknik Dasar Menggiring Bola (Dribbling); 5) Teknik Dasar Menembak (Shooting); 6) Teknik Menyundul Bola (Heading); 7) Latihan Untuk Kiper Futsal.

Dari berbagai pendapat ahli diatas peneliti dapat menyimpulkan beberapa aspek pada teknik dasar futsal bisa disederhanakan kembali melihat karakteristik dan manfaatnya yang hampir sama. Menurut peneliti, teknik dasar futsal bisa disederhanakan menjadi enam poin saja, yaitu: 1) Mengumpan bola atau passing; 2) Menerima bola atau control/receiving; 3) Menggiring bola atau dribbling; 4) Menendang bola atau shooting; 5) Pengenalan dengan bola atau Ball Feeling Latihan untuk penjaga gawang

\section{METODE}

Penelitian ini merupakan penelitian deskriptif. Menurut Ali Maksum (2012) menyatakan bahwa penelitian deskriptif adalah penelitian yang dilakukan untuk menggambarkan gejala, fenomena atau peristiwa tertentu. Pengumpulan data dilakukan untuk mendapatkan informasi terkait dengan fenomena kondisi, atau variabel tertentu dan tidak dimaksudkan untuk melakukan pengujian hipotesis.

Pendekatan penelitian ini menggunakan pendekatan survei. Menurut Suharsimi Arikunto (2010) Survei merupakan penelitian yang biasa dilakukan dengan subjek yang banyak, dimaksudkan untuk mengumpulkan informasi mengenai status gejala pada waktu penelitian berlangsung. Informasi yang diperoleh dari penelitian survei dapat dikumpulkan dari seluruh populasi dan dapa pula dari sebagian populasi.

Lokasi pelaksanaan penelitian dilaksanakan di GOR SOKA Bangkalan selama proses latihan tim PORPROV futsal Kabupaten Bangkalan. Populasi dalam penelitian ini adalah seluruh atlet futsal Kabupaten Bangkalan yang mengikuti PORPROV tahun 2019 sejumlah 16 atlet. Berdasarkan penggunaan subjek penelitian dan juga jumlah populasi, penelitian ini termasuk dalam peneltian populasi karena menurut Suharsimi Arikunto (2010) jika subjeknya kurang dari 100 orang sebaiknya diambil semua, jika subjeknya besar atau lebih dari 100 orang dapat diambil $10-15 \%$ atau 20 $25 \%$ atau lebih.

instrumen pengumpulan data adalah alat bantu yang dipilih dan digunakan oleh peneliti dalam kegiatannya mengumpulkan data agar kegiatan tersebut menjadi sistematis dan dipermudah olehnya. (Suharsimi Arikunto, 2010). Teknik pengumpulan data dalam penelitian ini menggunakan tes dan pengukuran:

1. Tes kelenturan menggunakan modifikasi tes sit and reach

2. Tes power tungkai mengunakan tes vertical jump

3. Tes kecepatan menggunakan tes lari 50 meter 
4. Tes kelincahan menggunakan tes llinois agulity run test

5. Tes daya tahan menggunakan Multistage fitnesh test (MFT)

Teknik analisis data yang digunakan dalam penelitian ini adalah statistik deskriptif. Statistik deskriptif menurut Sugiyono, (2014) adalah statistik yang digunakan untuk menganalisis data dengan cara mendeskripsikan atau menggambarkan data yang telah terkumpul sebagaimana adanya tanpa bermaksud membuat kesimpulan yang berlaku untuk umum atau generalisasi.

Rumus yang digunakan untuk menghitung persentase responden sebagai berikut:

$$
\mathrm{P}=\frac{F}{N} \times 100 \%
$$

Keterangan:

$\mathrm{P}=$ Persentase

$\mathrm{F}=$ Frekuensi

$\mathrm{N}=$ Jumlah responden

HASIL

Penelitian ini dilaksanakan di GOR SOKA Bangkalan selama proses latihan tim PORPROV futsal Kabupaten Bangkalan. Data penelitian ini terdiri dari: 1) Tes kelenturan menggunakan modifikasi tes sit and reach; 2) Tes power tungkai mengunakan tes vertical jump; 3) Tes kecepatan menggunakan tes lari 50 meter; 4) Tes kelincahan menggunakan tes Ilinois agulity run test; 5) Tes daya tahan menggunakan Multistage fitnesh test (MFT)

Tabel 1. Rangkuman Hasil Penelitian

\begin{tabular}{|c|c|c|c|c|c|}
\hline No & $\begin{array}{c}\text { Kelincahan } \\
\text { illinois test (detik) }\end{array}$ & $\begin{array}{c}\text { Kecepatan } \\
\text { S. } 50 \mathrm{~m} \text { (detik) }\end{array}$ & $\begin{array}{l}\text { Power } \\
\text { VJ }(\mathrm{cm})\end{array}$ & $\begin{array}{c}\text { Kelenturan } \\
\text { S\&R }(\mathrm{cm})\end{array}$ & $\begin{array}{c}\text { Daya Tahan } \\
\text { MFT (ml/kg/min) }\end{array}$ \\
\hline 1 & 14,31 & 6,8 & 25 & 36 & 54,4 \\
\hline 2 & 15,35 & 7 & 30 & 38,5 & 48,7 \\
\hline 3 & 14,45 & 6,9 & 35 & 37 & 47,8 \\
\hline 4 & 15,17 & 6,8 & 21 & 35,5 & 51,7 \\
\hline 5 & 15,08 & 6,7 & 34 & 35,5 & 47,8 \\
\hline 6 & 15,57 & 6,9 & 32 & 31,5 & 48,7 \\
\hline 7 & 14,85 & 6,9 & 25 & 35 & 44,1 \\
\hline 8 & 15,45 & 6,5 & 23 & 34 & 47,5 \\
\hline 9 & 15,38 & 6,9 & 24 & 35,5 & 45 \\
\hline 10 & 15,08 & 6,9 & 32 & 34 & 46,9 \\
\hline 11 & 15,39 & 6,9 & 25 & 30 & 48,7 \\
\hline 12 & 15,03 & 7 & 21 & 33 & 37,9 \\
\hline 13 & 14,12 & 6,5 & 31 & 37 & 51,7 \\
\hline 14 & 14,61 & 6,5 & 25 & 33 & 51,7 \\
\hline 15 & 17,14 & 7 & 29 & 33 & 36,2 \\
\hline 16 & 16,56 & 7 & 22 & 35 & 37,9 \\
\hline Mean & 15,22125 & 6,825 & 27,125 & 34,59375 & 46,66875 \\
\hline SD & 0,772294201 & 0,180739223 & 4,688638751 & 2,169629385 & 5,317608328 \\
\hline Min & 14,12 & 6,5 & 21 & 30 & 36,2 \\
\hline Maks & 17,14 & 7 & 35 & 38,5 & 54,4 \\
\hline
\end{tabular}

\section{Kelincahan}

Hasil perhitungan data kelincahan atlet PORPROV futsal Kabupaten Bangkalan tahun 2019 menghasilkan mean $=15,22$ median $=15,12$ modus $=15,08$ dan standar deviasi $=0,77$ sedangkan nilai terkecil $=17,14$ detik dan nilai terbesar= 14,12 detik. Tabel dristribusi kelincahan atlet PORPROV futsal Kabupaten Bangkalan tahun 2019 adalah sebagai berikut:
Berdasarkan tabel di atas terlihat bahwa sebagian besar kelincahan atlet PORPROV futsal Kabupaten Bangkalan tahun 2019 berada dalam kategori baik sekali dengan persentase sebesar $56,25 \%$. Berikut tampilan diagram batang data kelincahan atlet PORPROV futsal Kabupaten Bangkalan tahun 2019:

Tabel 2. Distribusi Frekuensi Kelincahan

\begin{tabular}{llccc}
\hline No & Kategori & Interval & Frekuensi & $(\%)$ \\
\hline $\mathbf{1}$ & Baik sekali & $<15,2$ & 9 & 56,25 \\
\hline $\mathbf{2}$ & Baik & $15,2-16,1$ & 5 & 31,25 \\
\hline $\mathbf{3}$ & Sedang & $16,2-18,1$ & 2 & 12,5 \\
\hline $\mathbf{4}$ & Kurang & $18,2-18,3$ & 0 & 0 \\
\hline $\mathbf{5}$ & Sangat kurang & $>18,3$ & 0 & 0 \\
\hline \multicolumn{7}{r}{ Jumlah } & & $\mathbf{1 6}$ & $\mathbf{1 0 0}$ \\
\hline
\end{tabular}




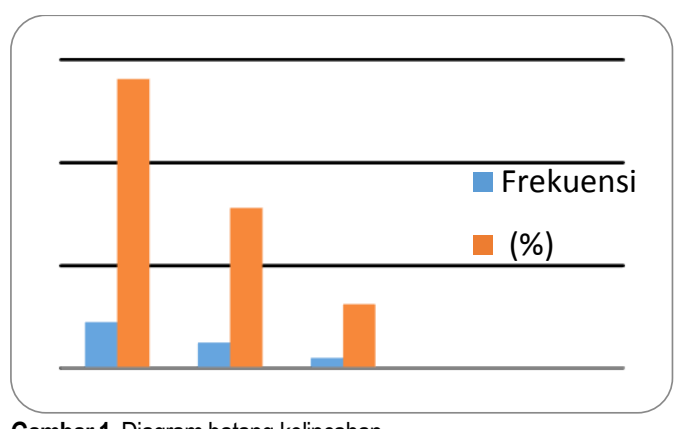

Gambar 1. Diagram batang kelincahan

\section{Kecepatan}

Hasil perhitungan data kecepatan atlet PORPROV futsal Kabupaten Bangkalan tahun 2019 menghasilkan mean $=6,8$ median $=6,9$ modus $=6,9$ dan standar deviasi $=0,18$ sedangkan nilai terkecil= 7 detik dan nilai terbesar $=6,5$ detik. Tabel dristribusi kecepatan atlet PORPROV futsal Kabupaten Bangkalan tahun 2019 adalah sebagai berikut:

Tabel 3. Distribusi Frekuensi Kecepatan

\begin{tabular}{llccc}
\hline No & Kategori & Interval & Frekuensi & $(\%)$ \\
\hline $\mathbf{1}$ & Baik sekali & $<6,7$ & 4 & 25 \\
\hline $\mathbf{2}$ & Baik & $6,8-7,6$ & 12 & 75 \\
\hline $\mathbf{3}$ & Sedang & $7,7-8,7$ & 0 & 0 \\
\hline $\mathbf{5}$ & Kurang & $8,8-10,3$ & 0 & 0 \\
\hline \multicolumn{7}{r}{ Sangat kurang } & $>10,4$ & 0 & 0 \\
\hline Jumlah & & $\mathbf{1 6}$ & $\mathbf{1 0 0}$ \\
\hline
\end{tabular}

Berdasarkan tabel di atas terlihat bahwa sebagian besar kecepatan atlet PORPROV futsal Kabupaten Bangkalan tahun 2019 berada dalam kategori baik dengan persentase sebesar $75 \%$. Berikut tampilan diagram batang data kecepatan atlet PORPROV futsal Kabupaten Bangkalan tahun 2019:

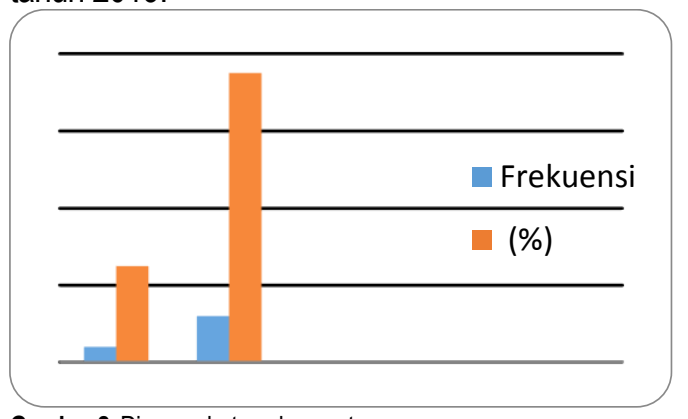

Gambar 2. Diagram batang kecepatan

\section{Power}

Hasil perhitungan data power atlet PORPROV futsal Kabupaten Bangkalan tahun 2019 menghasilkan mean $=27,1$ median $=25$ modus $=25$ dan standar deviasi $=4,69$ sedangkan nilai terkecil $=21 \mathrm{~cm}$ dan nilai terbesar $=35 \mathrm{~cm}$. Tabel dristribusi power atlet PORPROV futsal Kabupaten Bangkalan tahun 2019 adalah sebagai berikut:

\begin{tabular}{|c|c|c|c|c|}
\hline No & Kategori & Interval & Frekuensi & $(\%)$ \\
\hline 1 & Baik sekali & $>25$ & 11 & 68,75 \\
\hline 2 & Baik & $23-24$ & 2 & 12,5 \\
\hline 3 & Sedang & $19-22$ & 3 & 18,75 \\
\hline 4 & Kurang & $12-18$ & 0 & 0 \\
\hline 5 & Sangat kurang & $6-11$ & 0 & 0 \\
\hline \multicolumn{3}{|c|}{ Jumlah } & 16 & 100 \\
\hline
\end{tabular}

Berdasarkan tabel di atas terlihat bahwa sebagian besar power atlet PORPROV futsal Kabupaten Bangkalan tahun 2019 berada dalam kategori baik sekali dengan persentase sebesar $68,75 \%$. Berikut tampilan diagram batang data power atlet PORPROV futsal Kabupaten Bangkalan tahun 2019:

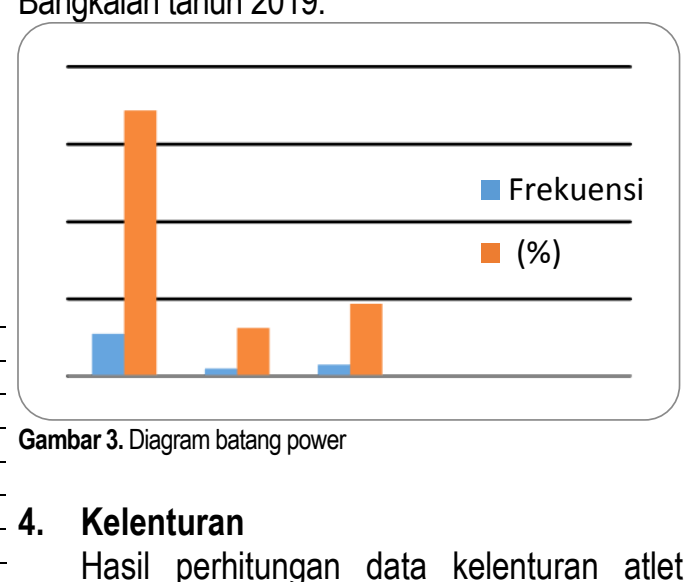
PORPROV futsal Kabupaten Bangkalan tahun 2019 menghasilkan mean $=34,5$ median $=35$ modus $=35,5$ dan standar deviasi $=2,16$ sedangkan nilai terkecil= $30 \mathrm{~cm}$ dan nilai terbesar= $38 \mathrm{~cm}$. Tabel dristribusi kelenturan atlet PORPROV futsal Kabupaten Bangkalan tahun 2019 adalah sebagai berikut:

Tabel 5. Distribusi Frekuensi Kelenturan

\begin{tabular}{llccc}
\hline No & Kategori & Interval & Frekuensi & $(\%)$ \\
\hline $\mathbf{1}$ & Baik sekali & $>41$ & 0 & 0 \\
\hline $\mathbf{2}$ & Baik & $31-40$ & 15 & 93,75 \\
\hline $\mathbf{3}$ & Sedang & $21-30$ & 1 & 6,25 \\
\hline $\mathbf{4}$ & Kurang & $11-20$ & 0 & 0 \\
\hline $\mathbf{5}$ & Sangat kurang & $<10$ & 0 & 0 \\
\hline \multicolumn{7}{r}{ Jumlah } & & $\mathbf{1 6}$ & $\mathbf{1 0 0}$ \\
\hline
\end{tabular}

Berdasarkan tabel di atas terlihat bahwa sebagian besar kelenturan atlet PORPROV futsal Kabupaten Bangkalan tahun 2019 berada dalam kategori baik dengan persentase sebesar $93,75 \%$. Berikut tampilan diagram batang data kelenturan atlet PORPROV futsal Kabupaten Bangkalan tahun 2019: 


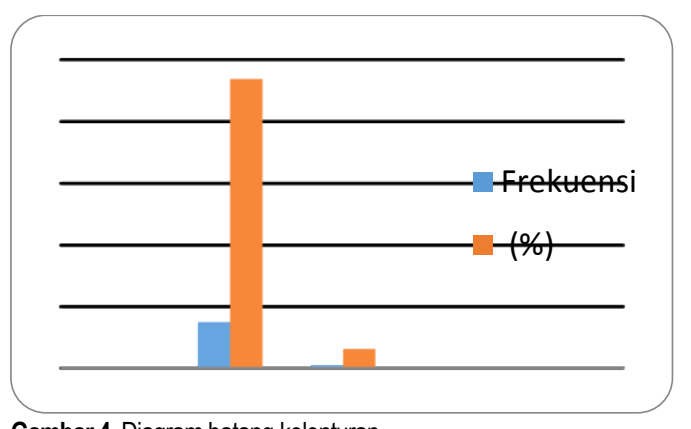

Gambar 4. Diagram batang kelenturan

\section{Daya Tahan}

Hasil perhitungan data daya tahan atlet PORPROV futsal Kabupaten Bangkalan tahun 2019 menghasilkan mean $=46,6$ median $=47,8$ modus $=48,7$ dan standar deviasi $=5,31$ sedangkan nilai terkecil $=36,2 \mathrm{ml} / \mathrm{kg} / \mathrm{min}$ dan nilai terbesar= $54,4 \mathrm{ml} / \mathrm{kg} / \mathrm{min}$. Tabel dristribusi daya tahan atlet PORPROV futsal Kabupaten Bangkalan tahun 2019 adalah sebagai berikut:

Tabel 6. Distribusi Frekuensi Daya Tahan

\begin{tabular}{|c|c|c|c|c|}
\hline No & Kategori & Interval & Frekuensi & $(\%)$ \\
\hline 1 & Baik sekali & $>51,6$ & 4 & 25 \\
\hline 2 & Baik & $42,6-51,5$ & 0 & 0 \\
\hline 3 & Sedang & $33,8-42,5$ & 9 & 56,25 \\
\hline 4 & Kurang & $25,0-33,7$ & 3 & 18,72 \\
\hline 5 & Sangat kurang & $<25,0$ & 0 & 0 \\
\hline \multicolumn{3}{|c|}{ Jumlah } & 16 & 100 \\
\hline
\end{tabular}

Berdasarkan tabel di atas terlihat bahwa sebagian besar daya tahan atlet PORPROV futsal Kabupaten Bangkalan tahun 2019 berada dalam kategori sedang dengan persentase sebesar $56,25 \%$. Berikut tampilan diagram batang data daya tahan atlet PORPROV futsal Kabupaten Bangkalan tahun 2019:

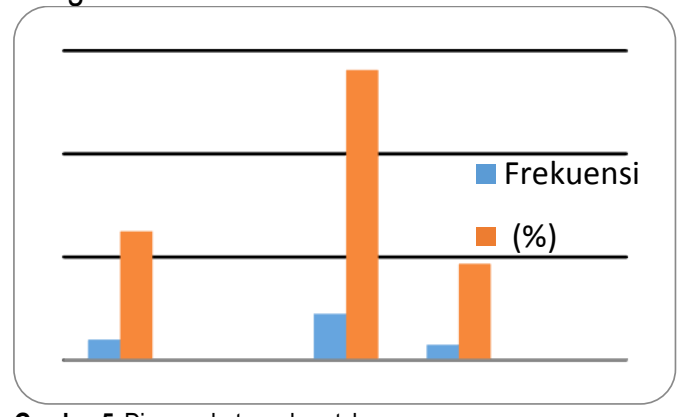

Gambar 5. Diagram batang daya tahan

\section{PENUTUP}

Dari analisis data, deskripsi dan pengujian hasil penelitian dapat diambil kesimpulan bahwa profil kondisi fisik atlet PORPROV futsal Kabupaten Bangkalan tahun 2019 dalam segi kelincahan termasuk dalam kategori baik sekali dengan persentase sebesar $56,25 \%$. Dalam segi kecepatan termasuk dalam kategori baik dengan persentase sebesar $75 \%$.
Dalam segi kelenturan termasuk dalam kategori baik sekali dengan persentase sebesar $68,75 \%$. Dalam segi power termasuk dalam kategori baik dengan persentase sebesar $93,75 \%$. Sedangkan dalam segi daya tahan termasuk dalam kategori sedang dengan persentase sebesar $56,25 \%$.

Menurut Justinus Lhaksana (2011), "Sehebatapapun seorang pemain dalam hal teknik dan taktik tetapi tanpa didasari oleh kondisi fisik yang baik maka prestasi yang akan diraih tidaklah sama dengan pemain yang memiliki kemampuan teknik, strategi dan tentunya kondisi fisik yang baik".

Melalui latihan fisik yang terprogram dan sesuai dengan kapasitas kemampuan pemain, diharapkan hasil dari latihan fisik tersebut dapat dilihat dari meningkatnya penampilan seorang pemain yang akhimya berdampak positif pada penampilan tim yang bermanfaat dalam suatu pertandingan.

Berdasarkan kesimpulan tersebut dapat menjadi bahan pertimbangan dalam latihan kondisi fisik atlet PORPROV futsal Kabupaten Bangkalan tahun 2019 agar dapat mencapai hasil yang lebih maksimal.

\section{DATAR PUSTAKA}

Arikunto, S. (2010). Prosedur Penelitian Suatu Pendekatan Praktik. Jakarta: PT Rineka Cipta.

Harsono. (2015). Kepelatihan Olahraga. Bandung: PT. Remaja Rosdakarya.

John D. Tenang. (2008). Mahir Bermain Futsal. Bandung: DAR. Mizan.

Lhaksana, J. (2011). Taktik dan Strategi FUTSAL Modern. Depok: Be Champion.

Maksum, A. (2012). Metodologi Penelitian dalam Olahraga. Surabaya: Unesa University Press.

Mulyono, M.A (2014). Buku Pintar Panduan Futsal. Jakarta Timur: Laskar Aksara.

Robbins, S.P dan Judge T.A. 2015. Perilaku Organisasi. Jakarta: Salemba Empat.

Sugiyono. (2014). Metode Penelitian Pendidikan Pendekatan Kuantitatif, Kualitatif, dan $R \& D$. Bandung: Alfabeta. 